\title{
Atendimento Educacional Especializado e Práticas Pedagógicas Inclusivas
}

\author{
Specialized Educational Service and Inclusive Pedagogical Practices
}

Servicio Educativo Especializado y Prácticas Pedagógicas Inclusivas

Carlo Schmidt

Professor doutor na Universidade Federal de Santa Maria, Santa Maria, RS, Brasil.

Editor-chefe da Revista Educação Especial.

E-mail: carlo.schmidt@ufsm.br ORCID: https://orcid.org/0000-0003-1352-9141

\section{Eliana da Costa Pereira de Menezes}

Professora doutora na Universidade Federal de Santa Maria, Santa Maria, RS, Brasil.

Editora-chefe da Revista Educação Especial.

E-mail: elianacpm@hotmail.com ORCID: https://orcid.org/0000-0002-5908-0039

\section{Clenio Perlin Berni}

Técnico administrativo em educação na Universidade Federal de Santa Maria, Santa Maria, RS, Brasil.

Editor-gerente da Revista Educação Especial.

Email: clenioberni@gmail.com ORCID: https://orcid.org/0000-0002-1267-0357

\section{Carla Luciane Blum Vestena (Org.)}

Professora doutora na Universidade Estadual do Centro-Oeste, Guarapuava, PR, Brasil.

E-mail: cvestena@unicentro.br ORCID: https://orcid.org/0000-0002-8655-7840

Carla Maria de Schipper (Org.)

Professora doutora na Universidade Estadual do Centro-Oeste, Guarapuava, PR, Brasil.

E-mail: carlaschipper@gmail.com ORCID: https://orcid.org/000-0002-4805-840x

Bernadete de Fatima Bastos Valentim (Org.)

Professora doutora na Universidade Estadual do Centro-Oeste, Guarapuava, PR, Brasil.

E-mail: bfbvalentim@gmail.com ORCID: https://orcid.org/0000-0002-2521-6540

\section{Editorial}

Com satisfação e alegria apresentamos à comunidade científica e acadêmica, bem como à sociedade, o Dossiê "Atendimento Educacional Especializado e Práticas Pedagógicas Inclusivas", contendo discussões acerca do atendimento educacional especializado e suas práticas inclusivas.

Este dossiê compõe-se de estudos e resultados de pesquisas realizadas com estudantes público-alvo da educação especial inclusiva, desde a infância, até a idade adulta - da educação básica à universidade, com resultados de abrangência internacional e nacional, de todas as regiões brasileiras.

O Atendimento Educacional Especializado ( $A E E$ ) é parte integrante do processo educacional e não deve ser negligenciado, tampouco permitir retrocessos a etapas já 
superadas, mas, deve-se garantir a implantação e a continuidade de serviços de apoio especializado que permitam eliminar todo tipo de barreiras de acesso à escolarização, garantindo a inclusão.

Ofertar serviços de forma equitativa frente à diversidade, seja de modo complementar ou suplementar abre oportunidades de avanço, ou, em tempos de retrocessos, de resistência diante de políticas públicas integradoras. Sendo assim, a publicação destas pesquisas contribuirá para a visibilidade do público que compõe a educação especial e inclusiva e de luta por direitos.

A prática do fazer inclusivo engloba uma complexidade de elementos que exige dos profissionais da educação atitudes positivas frente à diversidade, conhecimentos teóricos e práticos e capacidade de organização e sistematização pedagógica.

Deste modo, o presente dossiê se constitui um importante meio de disseminar pesquisas na área e contribuir para que a transversalidade da educação especial desde a educação infantil até o ensino superior, seja realizada de forma contínua, efetiva e com qualidade.

Boa leitura!

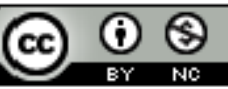
4.0 International (CC BY-NC 4.0) 